\title{
Discovery of quantitative trait loci for resistance to parasitic nematode infection in sheep: I. Analysis of outcross pedigrees
}

\author{
Allan M Crawford*1, Korena A Paterson2 ${ }^{2}$ Ken G Dodds', Cristina Diez Tascon ${ }^{2,5}$, \\ Penny A Williamson ${ }^{2}$, Meredith Roberts Thomson ${ }^{2}$, Stewart A Bisset ${ }^{3}$, Anne E Beattie ${ }^{1}$, \\ Gordon J Greer ${ }^{1}$, Richard S Green ${ }^{3}$, Roger Wheeler ${ }^{4}$, Richard J Shaw ${ }^{3}$, Kevin Knowler ${ }^{4}$ and \\ John C McEwan ${ }^{1}$
}

Address: ${ }^{1}$ AgResearch, Invermay Agricultural Centre, Private Bag 50034, Mosgiel, New Zealand, ${ }^{2}$ AgResearch, Molecular Biology Unit, Department of Biochemistry, University of Otago, Box 56, Dunedin, New Zealand, ${ }^{3}$ AgResearch, Wallaceville Animal Research Centre, PO Box 40063 , Upper Hutt, New Zealand, ${ }^{4}$ AgResearch, Woodlands, Private Bag 90121, Invercargill, New Zealand and 5 Banco de Tumores, Anatomia Patologica, Complejo Hospitalario de Leon, 24008 Leon, Spain

Email: Allan M Crawford* - allan.crawford@agresearch.co.nz; Korena A Paterson - korena.paterson@agresearch.co.nz; Ken G Dodds - ken.dodds@agresearch.co.nz; Cristina Diez Tascon - cdiez@hleo.sacyl.es; Penny A Williamson - nickandpen@e3.net.nz; Meredith Roberts Thomson - meredith_rt@hotmail.com; Stewart A Bisset - stewart.bisset@agresearch.co.nz; Anne E Beattie - anne.beattie@agresearch.co.nz; Gordon J Greer - gordon.greer@agresearch.co.nz; Richard S Green - richard.green@agresearch.co.nz; Roger Wheeler - roger.wheeler@agresearch.co.nz; Richard J Shaw - richard.shaw@agresearch.co.nz; Kevin Knowler - kevin.knowler@agresearch.co.nz; John C McEwan - john.mcewan@agresearch.co.nz

* Corresponding author

Published: 18 July 2006

Received: 03 March 2006

BMC Genomics 2006, 7:178 doi:10.1186/1471-2164-7-178

Accepted: 18 July 2006

This article is available from: http://www.biomedcentral.com//47/-2/64/7/178

(c) 2006 Crawford et al; licensee BioMed Central Ltd.

This is an Open Access article distributed under the terms of the Creative Commons Attribution License (http://creativecommons.org/licenses/by/2.0), which permits unrestricted use, distribution, and reproduction in any medium, provided the original work is properly cited.

\begin{abstract}
Background: Currently most pastoral farmers rely on anthelmintic drenches to control gastrointestinal parasitic nematodes in sheep. Resistance to anthelmintics is rapidly increasing in nematode populations such that on some farms none of the drench families are now completely effective. It is well established that host resistance to nematode infection is a moderately heritable trait. This study was undertaken to identify regions of the genome, quantitative trait loci (QTL) that contain genes affecting resistance to parasitic nematodes.

Results: Rams obtained from crossing nematode parasite resistant and susceptible selection lines were used to derive five large half-sib families comprising between 348 and 101 offspring per sire. Total offspring comprised 940 lambs. Extensive measurements for a range of parasite burden and immune function traits in all offspring allowed each lamb in each pedigree to be ranked for relative resistance to nematode parasites.

Initially the 22 most resistant and 22 most susceptible progeny from each pedigree were used in a genome scan that used 203 microsatellite markers spread across all sheep autosomes. This study identified 9 chromosomes with regions showing sufficient linkage to warrant the genotyping of all offspring. After genotyping all offspring with markers covering Chromosomes I, 3, 4, 5, 8, 12, 13, 22 and 23, the telomeric end of chromosome 8 was identified as having a significant QTL for parasite resistance as measured by the number of Trichostrongylus spp. adults in the abomasum and small intestine at the end of the second parasite challenge. Two further QTL for associated immune function traits of total serum $\operatorname{lgE}$ and $T$. colubiformis specific serum $\operatorname{lgG}$, at the end of the second parasite challenge, were identified on chromosome 23.

Conclusion: Despite parasite resistance being a moderately heritable trait, this large study was able to identify only a single significant $\mathrm{QTL}$ associated with it. The QTL concerned adult parasite burdens at the end of the second parasite challenge when the lambs were approximately 6 months old. Our failure to discover more QTL suggests that most of the genes controlling this trait are of relatively small effect. The large number of suggestive QTL discovered (more than one per family per trait than would be expected by chance) also supports this conclusion.
\end{abstract}




\section{Background}

Nematode parasites are the major animal health constraint in sheep production on pasture. Chemical control using anthelmintic drenches has been a reliable means of nematode control for the last 40 years but increasingly nematodes are becoming resistant to anthelmintics. A recent survey in New Zealand [1] has shown that approximately $43 \%$ and $33 \%$ of farms have nematodes resistant to benzimidazoles and macrocyclic lactones respectively. Nematodes resistant to all major classes of anthelmintics have now been documented throughout the world for the three major sheep nematode species - Haemonchus contortus, Teladorsagia circumcincta and Trichostrongylus colubriformis [2]. Multiply drug-resistant $H$. contortus is now making small ruminant production, in some areas of the tropics, unsustainable [3-5].

As a result of this failure of anthelmintic drenches, a major research effort has been underway for the past 15 years to examine alternatives to chemical control. The use of nematode trapping fungi [6], diets high in condensed tannins $[7,8]$, and other plant materials [9] as well as other nutritional approaches $[10,11]$ have all been examined as possible approaches to reduce the impact of nematode parasites in sheep.

A particularly popular nematode control method has been to select sheep which are genetically resistant to parasitic nematodes. This has the advantage of providing a long-term solution which involves challenging and phenotyping only a small proportion of the industry flocks, as the trait can be easily disseminated through the sale of resistant rams [12]. In New Zealand and Australia, lines of sheep selected for resistance and susceptibility to nematode parasites have been in existence since 1979 and 1975 respectively [13]. In addition, industry wide schemes, WormFEC in NZ [14] and NEMESIS in Australia [15], have been operating for more than a decade to help sheep breeders select for this trait.

A wide range of studies in many different sheep breeds has shown that resistance to nematode parasites is a moderately heritable trait with most heritability estimates about 0.3 [16-19]. Certain sheep breeds have also been identified as being more resistant to nematodes than others. For example the Red Massai sheep in Kenya have been shown to be more resistant to Haemonchus infection than the South African Dorper breed [16]. French scientists have shown that the Barbados Black Belly sheep is more resistant than the INRA401 composite breed [20].

The major method of measuring parasite burden is by counting parasite eggs in sheep faeces, the so called faecal egg count (FEC), which is an unattractive and labour intensive technique. Furthermore the parasite challenge required can affect lamb growth and other important traits such as faecal soiling around the anus (dags). These constraints have limited the uptake of parasite resistance selection by the sheep breeding industry. A proposed solution to this dilemma has been to try to identify the genes responsible for the heritable trait and offer a more attractive DNA test to help identify resistant sheep [21].

In order to identify suitable DNA markers a number of association studies have been undertaken with markers from the MHC region on sheep chromosome 20 [22-26]. Given that the development of an immune response is associated with resistance to nematodes it is not unexpected that associations have been identified with particular MHC markers or haplotypes. Most of the MHC marker associations have been in populations primarily infected with T. circumcincta. Markers located in the sheep gamma interferon gene on chromosome $3 \mathrm{q}$ have also shown significant associations with parasite resistance in Romney selection lines and wild populations of Soay sheep on the island of St Kilda off the west coast of Scotland. $[27,28]$

More global searches for DNA markers involving genome scans for QTL have also been undertaken. This is the fifth such study to be reported for parasite resistance in sheep. In all cases half-sib experimental pedigrees derived from a sire known to be segregating for parasite resistance were used, with the sires derived from crossing either divergent selection lines or crossing resistant and susceptible breeds of sheep. In the first study which used Merino sheep derived from crossing divergent selection lines and an artificial challenge with Trichostronglus colubriformis parasites no genome wide significant QTL were identified [29], although one region on chromosome 6 was significant at the chromosome wide level. In the second study Merino sheep were artificially challenged with $H$. contortus on 2 separate occasions at 6 months and 13 months of age. Four half-sib pedigrees were involved and a number of QTL were identified, but unfortunately their chromosomal location was not disclosed [30]. The third study involved the use of resistant Indonesian Thin Tail sheep crossed with susceptible Merino sheep and backcrossed to Merino sheep. Two artificial challenges with $H$. contortus larvae 12 weeks apart followed by measurement of faecal egg counts and blood packed cell volume (PCV) were used to generate and measure the parasite burden. As with the previous study, two QTL were identified but their chromosomal location was not disclosed [31].

The fourth study recently published by Davies et al [32] was the most similar to this one in that natural exposure to parasites by grazing was the method of infection. They identified QTL on chromosome 3 and 20 associated with specific IgA activity, on chromosome 2, 3 and 14 associ- 
ated with Nematodirus FEC and on chromosome 3 and 20 associated with Strongyle FEC.

This study reports in full our linkage analysis involving 5 half-sib pedigrees in which sires derived from crossing resistant and susceptible lines of Romney sheep were outcrossed to Coopworth ewes and a total of 18 different measurements for parasite burden and associated traits were used to define the phenotype in the offspring.

\section{Results}

\section{Initial genome scan results}

Decreases in the nematode parasite burden, as measured by FEC and internal worm numbers (the late larval stages and adult worms in the abomasum and small intestine), were the major phenotypes used to measure parasite burden and hence resistance. Given the very high cost of developing the large pedigrees used in this experiment we also measured the humoral immune response, both IgG and IgE, to the parasite challenge, the development of dags and lamb growth rate in the hope that these associated phenotypes may also provide some insight into the genetic basis of parasite resistance. We did however concentrate on parasite burden as the primary trait of interest so that in choosing the most extreme animals for this trait for genotyping we were reducing our chances of finding QTL for the other traits examined.

Results from the initial genome scan using the 44 most extreme offspring in the five pedigrees and the FEC1 and FEC2 traits, indicated the possibility of QTL for parasite resistance on chromosomes 1q, 3, 4, 5, 8, 12, 13, 20 and 23. Subsequently all progeny were genotyped with the markers used on these eight chromosomes. Given the very large number of phenotype and genotype measurements taken the results of all the analyses undertaken are presented in additional chromosome figures with results from each of the 26 chromosomes presented in a series of 21 graphs. [Additional files 6 to 31] The first graph in the series shows the information content across the chromosome; the second and third graphs show the linkage results for all traits from all families combined; the remaining 18 graphs show within family linkage for each of the traits measured. A full list of all microsatellite markers used in the genome scan is also included as Additional Table 1. [Additional file 3].

\section{QTL discoveries}

A total of six QTL with genome wide significance were identified and are summarised in Table 3. These results contain 4 QTL associated with parasite burden and 2 with the immune response to infection. No significant QTL were identified for growth rate or dag traits although as explained in the previous section we focussed our efforts on parasite burden in the search for QTL and it is only on those chromosomes in which all family members were genotyped where we had a good chance of discovering QTL for those traits not highly correlated with parasite burden.

The 2 most interesting QTL are those found in family 124 near the telomere on Chromosome 8. The two phenotypes are complementary in that one is a measure of Trichostrongylus spp adults and late stage larvae in the abomasum while the other is for the same nematode genus in the small intestine. The fact that two separate measures of parasite burden both show QTL in the same region of the genome strengthens the evidence for a QTL in this region. These two measures were moderately correlated (correlation of $0.49 ; \mathrm{P}<0.001$ after adjusting for fixed effects including sire but excluding QTL effects).

The across family QTL for Trichostrongylus spp adults in the small intestine on chromosome 11 and the family 124 QTL for Trichostrongylus spp adults in the abomasum on chromosome 2 are both on chromosomes where only the most extreme animals were genotyped. In our initial genome scan we obtained similar results on the 8 chromosomes intensively genotyped and with the exception of Chromosome 8 the QTL we identified were not confirmed by the additional genotyping. There is a good chance that the chromosome 11 and 2 QTL would not be confirmed by further genotyping.

The two QTL in family 154 on Chromosome 23 are both concerned with the immune response to parasite infection measuring either total serum IgE or serum IgGspecific for the T. colubriformis L3 larvae. These two phenotypes have a correlation of $0.25(\mathrm{P}<0.001)$. The QTL peaks, although approximately $30 \mathrm{cM}$ apart on this small chromosome, do overlap so we are unable to determine whether the same or different genes are responsible.

As expected with a genome scan involving a large number of measured traits, many suggestive QTL were also identified. We identified 21 of these across families combined (c.f. 26 expected if there are no true QTL) and 123 suggestive QTL within families (90 expected). All the suggestive QTL are indicated by an appropriately coloured asterisk above their most favoured position on the chromosome. The six significant QTL are indicated by a double asterisk.

\section{Discussion}

There is good evidence from a large range of studies in a variety of sheep populations, including the breeds used in this study [17], that parasite resistance is a moderately heritable trait. This indicates that genes and QTL affecting parasite resistance must exist. Unfortunately this study, involving almost 1000 sheep that were extensively phenotyped and genotyped, has only convincingly identified 
one QTL, on chromosome 8, for parasite resistance. The estimated size of the effect is a 2.3-fold reduction in adult worms and late stage larvae in the abomasum and small intestine in those sheep with the favourable allele, although this is likely to be an overestimate [33].

A further two QTL were identified for associated traits (specific anti- T. colubriformis IgG $_{1}$ and total IgE in serum) involved in the immune response to parasite infection. Given that these two QTL are in regions without even suggestive parasite resistance QTL, it is unlikely that the genes affecting these traits directly affect parasite resistance.

It is possible that QTL are being masked by epistatic effects. The recent publication, by Carlborg et al,[34] in which epistasis models were used to find QTL with major effect on chicken growth is encouraging. The data used was from a traditional linkage study which had found no large QTL when modelling a single QTL [35]. The aim of our experiment was to find QTL that could be used in selection schemes without regard to other QTL. Although a single QTL analysis has not revealed any QTL worth pursuing for this purpose, it may be that there are sets of two or more QTL with large combined effects. Such effects could be revealed by scanning for two QTL simultaneously and we plan to undertake such an analysis. This analysis is likely to uncover only very large effects with the present experiment given the smaller subclass sizes involved and the need for stricter testing thresholds to account for the increased number of multiple tests.

The simplest explanation for the small number of identified QTL is that the genes affecting resistance are of small effect. Power calculations indicate that, at the average family size, this genome scan would have a $90 \%$ chance of detecting any QTL with an effect greater than $0.8 \sigma_{p}$. Given the very high cost of this experiment the option of trebling the size of pedigrees, so that QTL with effects as small as $0.5 \sigma_{\mathrm{p}}$ can be reliably identified, is not attractive.

A more attractive alternative is to switch discovery strategies and use linkage disequilibrium or allele association studies to find chromosomal regions and genes affecting resistance to parasites. The recent development of highthroughput systems for genotyping Single Nucleotide Polymorphisms (SNP's) [36] means that large scale allele association studies are now possible. Recent studies [37] have shown that sheep populations have high levels of linkage disequilibrium meaning that 10-20 thousand SNP markers are likely to define most of the haplotype blocks segregating in the sheep genome. Providing the sheep genomics community can generate a large number of SNP markers suitable for high-throughput genotyping, this approach is feasible. Strategies involving linkage disequilibrium analysis using large numbers of SNP's geno- typed across well phenotyped unrelated sheep may be more successful than ours and others linkage studies.

\section{Conclusion}

Despite being a moderately heritable trait this large study was only able to identify a single significant QTL for Trichostrongylus spp. resistance in those regions where we had chosen to genotype all the animals. The QTL concerned adult parasite burdens at the end of the second parasite challenge when lambs are approximately 6 months old. Our failure to discover more QTL suggests that most of the genes controlling this trait are of relatively small effect hence we conclude that discovery strategies using linkage analysis should be replaced by strategies using linkage disequilibrium in unrelated populations.

\section{Methods}

\section{Selection lines and outcross segregation pedigrees}

The Wallaceville divergent FEC selection lines of Romneys commenced in 1979 [38]. Selection is currently based on FEC levels after natural challenge, measured twice during the first 8 months of life, in both ram and ewe lambs. At present, the high line has a 40-fold higher FEC than the low line during the autumn. On a logarithmic scale this translates to a $3.6 \sigma_{p}$ divergence between lines (C.A. Morris, unpublished data). Rams used as the sires of five large half-sib families (Table 1.) were derived from reciprocal crosses of the selection lines. The parents of these rams were born in either 1992 or 1993 and at this stage in the development of the selection lines there would have had an average 8-fold difference in FEC between the lines which equates to $2.6 \sigma_{\mathrm{p}}$. Studies in these lines have shown FEC to be highly correlated $(r=0.85-0.91)$ with Trichostrongyle adult worm burden in the intestine [39]. The lambs were generated in 1993 and 1994 on two separate properties in Southland New Zealand by mating the F1 rams to unrelated Coopworth ewes, a composite breed derived from Romney and Border Leicester interbreds.

\section{Parasite challenges}

Two natural field challenges of infective nematode larvae [38] were given to all outcross lambs. Challenge 1 - after weaning, lambs were drenched with $9 \mathrm{ml}$ of ivermectin (Ivomec liquid, Merial New Zealand) then grazed on pasture known to be contaminated with parasite larvae. A

Table I: Half-sib outcross sheep families used to detect QTL for disease resistance

\begin{tabular}{lll}
\hline Family & Sire & Number of progeny \\
\hline 1 & $92 / 0066$ & 225 \\
2 & $92 / 0153$ & 175 \\
3 & $92 / 0154$ & 348 \\
4 & $92 / 0155$ & 111 \\
5 & $93 / 0124$ & 101 \\
\hline
\end{tabular}


subset of the lambs were monitored weekly by faecal sampling until the average strongyle egg count approached 1500 eggs per gram of faecal material (epg), then all lambs were measured. Three separate faecal samples were taken over 5 days and results (in epg) averaged. Faecal egg counts were determined using a modified McMaster method [40] in which each egg counted represents 50 eggs per gram of faeces. Challenge $\mathbf{2}$ - After all the Challenge 1 faecal samples had been taken, lambs were again drenched (13 ml, ivermectin) then returned to contaminated pasture and monitored. When the parasite burden again reached approximately 1500 epg 3 more faecal samples were taken and measured as described for the first challenge. Mean strongyle and Nematodirus infection levels achieved were 1091 epg (FEC1) and 70 epg (NEM1) respectively for the first challenge and 1462 epg (FEC2) and 36 epg (NEM2) respectively for the second challenge.

After the completion of the second field challenge, and the collection of faecal samples, lambs were slaughtered. From each lamb, the abomasum and first $5 \mathrm{~m}$ of small intestine were collected with the ends sealed to retain the contents for analysis. Laboratory analysis of the contents was designed to count the number of large L4, L5 larvae and adult worms using the method of Robertson and Elliott [41]. Direct examination of the sexual organs of male adults was the method used to identify the genus of adult nematodes. A full description of all phenotypes measured and used in the QTL analysis is provided in Table 2

Table 2: A description of the phenotype measurements used in the linkage analysis and their associated abbreviation

\begin{tabular}{|c|c|c|c|}
\hline Abbreviation & Description of phenotype measurement & Units of measurement & $\sigma_{\mathrm{p}}^{*}$ \\
\hline DAG0 & Dag score at weaning & $0-5$ scale & 0.56 \\
\hline DAGI & Dag score at the end of the first parasite challenge & $0-5$ scale & 0.89 \\
\hline DAG2 & Dag score at the end of the second parasite challenge & $0-5$ scale & 0.82 \\
\hline ELISAI & IgG specific to T.colubriformis in serum collected at weaning & $\mathrm{OD}_{490}$ using reference sera as standards & 0.079 \\
\hline ELISA2 & IgG specific to T.colubriformis in serum collected 4 weeks after weaning & $\mathrm{OD}_{490}$ using reference sera as standards & 0.095 \\
\hline ELISA3 & $\begin{array}{l}\text { IgG specific to T.colubriformis in serum collected at the end of the first parasite } \\
\text { challenge }\end{array}$ & $\mathrm{OD}_{490}$ using reference sera as standards & 0.157 \\
\hline ELISA4 & $\begin{array}{l}\text { IgG specific to T.colubriformis in serum collected } 4 \text { weeks after the start of the } \\
\text { second field challenge }\end{array}$ & $\mathrm{OD}_{490}$ using reference sera as standards & 0.158 \\
\hline ELISA5 & $\begin{array}{l}\text { IgG specific to T.colubriformis in serum collected at the end of the second field } \\
\text { challenge }\end{array}$ & $\mathrm{OD}_{490}$ using reference sera as standards & 0.171 \\
\hline LAOST & $\begin{array}{l}\text { Log transformed estimates of } T \text {. circumcincta adults and late stage larvae found } \\
\text { in the abomasum collected at slaughter at the end of the second parasite } \\
\text { challenge }\end{array}$ & Number of individuals & 0.92 \\
\hline LATRICH & $\begin{array}{l}\text { Log transformed estimates of Trichostrongylus spp. adults and late stage larvae } \\
\text { found in the abomasum collected at slaughter at the end of the second parasite } \\
\text { challenge }\end{array}$ & Number of individuals & 0.69 \\
\hline LFECI & $\begin{array}{l}\text { Log transformed mean estimate of Strongyle eggs per gram of faecal material } \\
\text { collected and measured } 3 \text { times over five days at the end of the first parasite } \\
\text { challenge }\end{array}$ & Number of eggs per gram of faeces & $0.5 \mathrm{I}$ \\
\hline LFEC2 & $\begin{array}{l}\text { Log transformed mean estimate of Strongyle eggs per gram of faecal material } \\
\text { collected and measured } 3 \text { times over five days at the end of the second parasite } \\
\text { challenge }\end{array}$ & Number of eggs per gram of faeces & 0.68 \\
\hline LIGE & $\begin{array}{l}\text { Log transformed estimates of total lgE in serum collected at the end of the } \\
\text { second parasite challenge }\end{array}$ & $\mathrm{OD}_{450}$ using reference sera as standards & 0.70 \\
\hline LSINEM & $\begin{array}{l}\text { Log transformed estimates of Nematadirus sp. adults and late stage larvae found } \\
\text { in the small intestine collected at slaughter at the end of the second parasite } \\
\text { challenge }\end{array}$ & Number of individuals & 1.22 \\
\hline LSITRI & $\begin{array}{l}\text { Log transformed estimates of Trichostrongylus spp. adults and late stage larvae } \\
\text { found in the small intestine collected at slaughter at the end of the second } \\
\text { parasite challenge }\end{array}$ & Number of individuals & 0.82 \\
\hline SNEMI & $\begin{array}{l}\text { Scaled mean estimate of Nematodirus spp. eggs per gram of faecal material } \\
\text { collected and measured } 3 \text { times over five days at the end of the first parasite } \\
\text { challenge }\end{array}$ & Number of eggs per gram of faeces & 0.76 \\
\hline SNEM2 & $\begin{array}{l}\text { Scaled mean estimate of Nematodirus spp. eggs per gram of faecal material } \\
\text { collected and measured } 3 \text { times over five days at the end of the second parasite } \\
\text { challenge }\end{array}$ & Number of eggs per gram of faeces & 0.82 \\
\hline WTFEC2 & Liveweight of lambs at the end of the second parasite challenge & kilograms & 3.63 \\
\hline
\end{tabular}

$* \sigma_{\mathrm{p}}=$ residual $\mathrm{SD}$ from a model containing all fixed effects including sire (but no marker effects). 
Table 3: QTL Discovered with genome-wide significant linkage

\begin{tabular}{|c|c|c|c|c|c|c|}
\hline Chromosome & $\begin{array}{l}\text { Trait } \\
\text { Abbreviation }\end{array}$ & Sire & $\begin{array}{l}\text { Estimate of } \\
\text { effect } \pm \text { SE }\end{array}$ & Nearest marker & Bracketing markers & $\begin{array}{l}95 \% \text { Bootstrap } \\
\text { confidence interval }\end{array}$ \\
\hline 2 & LATRICH & 124 & $\mathrm{I} .63 \pm 0.4 \mathrm{I}$ & BM8II24 & $\mathrm{BMSI} 34 \mathrm{I} / \mathrm{HH} 30$ & BMSI34I - FCBII \\
\hline 8 & LATRICH & 124 & $0.82 \pm 0.20$ & BM32I5 & Telomere/BM4208 & Whole chromosome \\
\hline 8 & LSITRI & 124 & $0.87 \pm 0.24$ & BM32I5 & Telomere/BM4208 & Whole chromosome \\
\hline II & LSITRI & $\begin{array}{r}\text { All sires } \\
\text { combined }\end{array}$ & & BM9202 & Centromere/ETH3 & BM9202 - MB087 \\
\hline 23 & ELISA4 & 154 & $0.07 \pm 0.02$ & ILSTS65 & MCMAI/ADCYCAPI & CDT2 - ADCYAPI \\
\hline 23 & LIGE & 154 & $0.20 \pm 0.08$ & ILSTS42 & Centomere/BM226 & Whole chromosome \\
\hline
\end{tabular}

\section{Immunological response measurements}

T. colubriformis L3 total IgG antibodies [42] were measured by ELISA from serum samples taken on five separate occasions as follows: at weaning, at the end of the fourth week of the first field challenge, at the collection of the final faecal sample of the first field challenge, at the end of the fourth week of the second field challenge, and at the collection of the final faecal sample of the second field challenge just prior to slaughter. Total IgE in the serum was also measured [43] in the samples taken at the end of the second field challenge

\section{Other traits measured}

Liveweight measurements were taken at birth, weaning, and after each challenge. Dag scores were recorded at weaning, and after each challenge. Dagginess was measured by visual examination of the hindquarters of each lamb and a score given from 0 to 5 depending on the degree of faecal contamination of the skin and wool surrounding the anus, with $0=$ no contamination and $5=$ very heavily soiled hindquarters (SIL Technical Bulletin "Dag Score" at [44]).

\section{Genotyping}

All DNA markers used were microsatellites. The 5 sires were screened to determine whether each of the markers was heterozygous and if heterozygous the genotypes of the progeny determined. Initially only the 22 most resistant and 22 most susceptible progeny within each family were genotyped. These extremes were chosen on the basis of LFEC1, LFEC2, SNEM1 and SNEM2 after adjusting for fixed effects. The adjusted trait values were combined into a single trait for ranking. This trait was the first principal component (the linear combination that explains the most variation), i.e. $0.19 *$ adjusted LFEC1 $+0.47 *$ adjusted LFEC2 + $0.49 *$ adjusted SNEM1 + $0.71 *$ adjusted SNEM2. If some suggestion of linkage was identified on a particular chromosome after this initial screen all progeny were genotyped for all informative markers for this chromosome. The method of genotyping used radioactively labelled primers and $12 \%$ polyacrylamide sequencing gels to resolve the microsatellite allele sizes as described by Crawford et al. [45]. A complete list of all markers used in the genome screen is found in Additional Table 1 [Additional file 3].

With the exception of one marker developed as part of this project to improve the informativeness of Sheep chromosome 23 all information about the markers including, primer sequence, product sizes, and best $\mathrm{Mg++}$ concentration can be found at the following web address, [46]. The marker developed for the project is an (AC) $)_{n}$ microsatellite called Oar CDT2 and uses the primers 5'-CGTGCACAGAGATTGCATTC-3' and 5'-CACAGTATCAGTCAT CTCTAGCTCC-3'. The amplification conditions were as previously described[45]

\section{Statistical analysis}

Raw cohort means and standard deviations of the traits are shown in Additional Table 2. [Additional file 4] Correlations between traits, grouped into related sets, are shown in Additional Table 3 [Additional file 5]. Many of the traits were transformed to make the variance more homogeneous. Worm counts and FEC were transformed using natural logs, $\log _{e}(x+c)$, where $x$ is the count and $c$ is the unit count. Total IgE was also log transformed. Nematodirus counts were further transformed by scaling each cohort to the average standard deviation and modelling the standard deviation of cohorts as linearly related to their means.

Genotype data was checked as follows. Sire-offspring pairs were compared for consistency with Mendelian inheritance and sire families for equal segregation of sire alleles. Linkage maps were calculated using CRI-MAP [47] and orders and distances checked for consistency with the map of Maddox et al [48]. Potential errant genotypes were rescored, and when necessary parentage relationships excluded.

The information content [49] was calculated for each family, along each chromosome. Regions of low information 
content are usually where only the extreme progeny were genotyped, but may also indicate that the sire was not heterozygous for any markers in the region.

The QTL detection method used was least squares interval mapping, using the Haley-Knott regression methods [50]. Fixed effects fitted for all traits were sex, cohort (birth year $\mathrm{x}$ farm combination) and sire, as well as the covariate of birth day of year. The QTL effect was fitted as the probability of the progeny receiving a particular sire allele (arbitrarily chosen to be the paternal or maternal alleles for each sire), and fitted within sire. The model for WTFEC2 also included the birth/rearing rank combination (single/ single, multiple/single or multiple/multiple) and dam age ( 2 years or $>2$ years). The model for the ELISA traits also included the interaction between cohort and birth day.

The marker positions used were those estimated for male meioses, from [48] except that if a marker was not present on that map, its position was determined from the current population, and then placed on the map relative to markers of known position. Haley-Knott regression was performed at $2 \mathrm{cM}$ intervals and both within family and across family (i.e. genotype probability within family) statistics collected. Genome-wise significant $(\mathrm{P}<0.05)$ and suggestive (where the expected number of false positives is one) thresholds were determined by permutation methods [51] using 1000 permutations. Confidence intervals for the locations of significant QTL were found using bootstrap methods [52] using 500 replicates.

The suggestive and significant permutation thresholds for all traits and pedigree combinations are provided in Additional Figure 1 (All families combined) [Additional file 1] and Additional Figure 2 (each individual family) [Additional file 2]. These are compared to theoretical values derived using the methods of Lander and Kruglyak [53].

\section{Authors' contributions}

AMC: experimental design, genotype analysis and manuscript preparation; KAP: oversight of genotyping, marker development; KGD: experimental design and statistical analysis; CDT: genotyping, marker development; PAW: genotyping; MRT: genotyping, marker development; SAB: Selection line development and provision of F1 rams; AEB: Statistical analysis; GJG: Oversight of phenotype measurement; RSG: measurement of serum IgG; RW: animal husbandry and phenotype measurement; RJS: measurement of serum total IgE; KK: oversight of animal husbandry; JCM: conception of the experiment and overall management of project.

\section{Additional material}

\section{Additional File 1}

Additonal figure 1. Significance thresholds for each trait across all families as determined by permutation.

Click here for file

[http://www.biomedcentral.com/content/supplementary/1471-

2164-7-178-S1.pdf]

\section{Additional File 2}

Additonal figure 2. Significance thresholds for each trait/trait combination as determined by permutation.

Click here for file

[http://www.biomedcentral.com/content/supplementary/1471-

2164-7-178-S2.pdf]

\section{Additional File 3}

Additional table 1. List of all DNA markers used in the linkage analysis. Click here for file

[http://www.biomedcentral.com/content/supplementary/1471-

2164-7-178-S3.doc]

\section{Additional File 4}

Additional table 2. Raw means and standard deviations by cohort for traits analysed.

Click here for file

[http://www.biomedcentral.com/content/supplementary/1471-

2164-7-178-s4.doc]

\section{Additional File 5}

Additional table 3. Raw correlations between groups of traits. Click here for file

[http://www.biomedcentral.com/content/supplementary/1471-

2164-7-178-S5.doc]

\section{Additional File 6}

Chr 1. Haley Knott linkage analysis of sheep chromosome 1. Click here for file

[http://www.biomedcentral.com/content/supplementary/1471-

2164-7-178-S6.pdf]

\section{Additional File 7}

Chr 2. Haley Knott linkage analysis of sheep chromosome 2. Click here for file

[http://www.biomedcentral.com/content/supplementary/1471-

2164-7-178-S7.pdf]

\section{Additional File 8}

Chr 3. Haley Knott linkage analysis of sheep chromosome 3. Click here for file

[http://www.biomedcentral.com/content/supplementary/14712164-7-178-S8.pdf]

\section{Additional File 9}

Chr 4. Haley Knott linkage analysis of sheep chromosome 4. Click here for file

[http://www.biomedcentral.com/content/supplementary/14712164-7-178-S9.pdf] 


\section{Additional File 10}

Chr 5. Haley Knott linkage analysis of sheep chromosome 5.

Click here for file

[http://www.biomedcentral.com/content/supplementary/1471-

2164-7-178-S10.pdf]

\section{Additional File 11}

Chr 6. Haley Knott linkage analysis of sheep chromosome 6

Click here for file

[http://www.biomedcentral.com/content/supplementary/1471-

2164-7-178-S11.pdf]

\section{Additional File 12}

Chr 7. Haley Knott linkage analysis of sheep chromosome 7.

Click here for file

[http://www.biomedcentral.com/content/supplementary/14712164-7-178-S12.pdf]

\section{Additional File 13}

Chr 8. Haley Knott linkage analysis of sheep chromosome 8.

Click here for file

[http://www.biomedcentral.com/content/supplementary/1471-

2164-7-178-S13.pdf]

\section{Additional File 14}

Chr 9. Haley Knott linkage analysis of sheep chromosome 9

Click here for file

[http://www.biomedcentral.com/content/supplementary/1471-

2164-7-178-S14.pdf]

\section{Additional File 15}

Chr 10. Haley Knott linkage analysis of sheep chromosome 10. Click here for file

[http://www.biomedcentral.com/content/supplementary/1471-

2164-7-178-S15.pdf]

\section{Additional File 16}

Chr 11. Haley Knott linkage analysis of sheep chromosome 11. Click here for file

[http://www.biomedcentral.com/content/supplementary/1471-

2164-7-178-S16.pdf]

\section{Additional File 17}

Chr 12. Haley Knott linkage analysis of sheep chromosome 12.

Click here for file

[http://www.biomedcentral.com/content/supplementary/1471-

2164-7-178-S17.pdf]

\section{Additional File 18}

Chr 13. Haley Knott linkage analysis of sheep chromosome 13.

Click here for file

[http://www.biomedcentral.com/content/supplementary/1471-

2164-7-178-S18.pdf]

\section{Additional File 19}

Chr 14. Haley Knott linkage analysis of sheep chromosome 14.

Click here for file

[http://www.biomedcentral.com/content/supplementary/1471-

2164-7-178-S19.pdf]

\section{Additional File 20}

Chr 15. Haley Knott linkage analysis of sheep chromosome 15. Click here for file

[http://www.biomedcentral.com/content/supplementary/14712164-7-178-S20.pdf]

\section{Additional File 21}

Chr 16. Haley Knott linkage analysis of sheep chromosome 16. Click here for file

[http://www.biomedcentral.com/content/supplementary/14712164-7-178-S21.pdf]

\section{Additional File 22}

Chr 17. Haley Knott linkage analysis of sheep chromosome 17. Click here for file

[http://www.biomedcentral.com/content/supplementary/14712164-7-178-S22.pdf]

\section{Additional File 23}

Chr 18. Haley Knott linkage analysis of sheep chromosome 18. Click here for file [http://www.biomedcentral.com/content/supplementary/14712164-7-178-S23.pdf]

\section{Additional File 24}

Chr 19. Haley Knott linkage analysis of sheep chromosome 19. Click here for file

[http://www.biomedcentral.com/content/supplementary/14712164-7-178-S24.pdf]

\section{Additional File 25}

Chr 20. Haley Knott linkage analysis of sheep chromosome 20. Click here for file

[http://www.biomedcentral.com/content/supplementary/14712164-7-178-S25.pdf]

\section{Additional File 26}

Chr 21. Haley Knott linkage analysis of sheep chromosome 21 Click here for file [http://www.biomedcentral.com/content/supplementary/14712164-7-178-S26.pdf]

\section{Additional File 27}

Chr 22. Haley Knott linkage analysis of sheep chromosome 22. Click here for file [http://www.biomedcentral.com/content/supplementary/14712164-7-178-S27.pdf]

\section{Additional File 28}

Chr 23. Haley Knott linkage analysis of sheep chromosome 23. Click here for file [http://www.biomedcentral.com/content/supplementary/14712164-7-178-S28.pdf]

\section{Additional File 29}

Chr 24. Haley Knott linkage analysis of sheep chromosome 24. Click here for file [http://www.biomedcentral.com/content/supplementary/14712164-7-178-S29.pdf] 


\section{Additional File 30 \\ Chr 25. Haley Knott linkage analysis of sheep chromosome 25. \\ Click here for file \\ [http://www.biomedcentral.com/content/supplementary/1471- \\ 2164-7-178-S30.pdf] \\ Additional File 31 \\ Chr 26. Haley Knott linkage analysis of sheep chromosome 26. \\ Click here for file \\ [http://www.biomedcentral.com/content/supplementary/1471- \\ 2164-7-178-S31.pdf]}

\section{Acknowledgements}

We wish to thank the following people for their contribution: Melanie TayIor, MAFQual, Dianne Squire, Alex Vlassoff and Chris West, AgResearch Wallaceville, Craig Wright, University of Otago and Chris Morris, AgResearch Ruakura. This work was funded by grants from the NZ Foundation for Research Science and Technology

\section{References}

I. Hughes PL, McKenna PB, Dowling AF: A survey of the prevalence of emerging macrocyclic lactone resistance and of benzimidazole resistance in sheep nematodes in the lower North Island of New Zealand. New Zealand Veterinary Journal 2005, 53(I):87-90.

2. Kaplan RM: Drug resistance in nematodes of veterinary importance: a status report. Trends Parasitol 2004 20(10):477-48I.

3. Waller PJ, Echevarria F, Eddi C, Maciel S, Nari A, Hansen JW Anthelmintic resistance of nematodes in sheep flocks in South America. Veterinary Record 1995, I 36(24):620.

4. Waller PJ, Echevarria F, Eddi C, Maciel S, Nari A, Hansen JW: The prevalence of anthelmintic resistance in nematode parasites of sheep in southern Latin America: general overview. Veterinary Parasitology 1996, 62:181-187.

5. Nari A, Salles J, Gil A, Waller PJ, Hansen JW: The prevalence of anthelmintic resistance in nematode parasites of sheep in southern Latin America: Uruguay. Veterinary Parasitology 1996, 62:213-222.

6. Waghorn TS, Leathwick DM, Chen LY, Skipp RA: Efficacy of the nematode-trapping fungus Duddingtonia flagrans against three species of gastro-intestinal nematodes in laboratory faecal cultures from sheep and goats. Veterinary Parasitology 2003, I I 8(3-4):227-234.

7. Paolini V, De La Farge F, Prevot F, Dorchies P, Hoste H: Effects of the repeated distribution of sainfoin hay on the resistance and the resilience of goats naturally infected with gastrointestinal nematodes. Veterinary Parasitology 2005, I27(34):277-283.

8. Niezen JH, Charleston WAG, Robertson HA, Shelton D, Waghorn GC, Green R: The effect of feeding sulla (Hedysarum coronarium) or lucerne (Medicago sativa) on lamb parasite burdens and development of immunity to gastrointestinal nematodes. Veterinary Parasitology 2002, I 05(3):229-245.

9. Hounzangbe A, Zinsou FE, Hounpke V, Moutairou K, Hoste H: In vivo effects of Fagara leaves on sheep infected with gastrointestinal nematodes. Tropical Animal Health and Production 2005, 37(3):205-2|4.

10. Walkden BSW, Eady SJ: Nutritional influences on the expression of genotypic resistance to gastrointestinal nematode infection in sheep. In Australian Journal of Experimental Agriculture Volume 43. Issue 12 Collingwood; Australia , CSIRO Publishing; 2003:|445-|454

II. Valderrabano J, Delfa $R$, Uriarte J: Effect of level of feed intake on the development of gastrointestinal parasitism in growing lambs. Veterinary Parasitology 2002, I04(4):327-338.
12. McEwan JC: Breeding for ovine host resistance to gastrointestinal parasitism. Proceedings from the 28th seminar of the Society of Sheep and Beef Cattle Veterinarians NZVA 1998:47-56.

13. Morris CA, Vlassoff A, Bisset SA, Baker RL, West C], Hurford AP: Responses of Romney sheep to selection for resistance or susceptibility to nematode infection. Animal Science 1997, 64(2):319-329.

14. Bisset SA, Morris CA, McEwan JC, Vlassoff A: Breeding sheep in New Zealand that are less reliant on anthelmintics to maintain health and productivity. New Zealand Veterinary Journal 200I, 49(6):236-246

15. Eady SJ, Woolaston RR, Lewer RP, Raadsma HW, Swan AA, Ponzoni RW: Resistance to nematode parasites in Merino sheep: correlation with production traits. Australian Journal of Agricultural Research 1998, 49(8): |20|-|2||.

16. Baker RL, Mwamachi DM, Audho JO, Aduda EO, Thorpe W: Genetic resistance to gastro-intestinal nematode parasites in Red Maasai, Dorper and Red Maasai x Dorper ewes in the sub-humid tropics. Animal Science 1999, 69(2):335-344.

17. Bissett SA, Vlassoff A, Morris CA, Southey BR, Baker RL, Parker AGH: Heritability and genetic correlations among faecal egg counts and productivity traits in Romney sheep. New Zealand Journal of Agricultural Research 1992, 35(I):5I-58.

18. Bouix J, Krupinski J, Rzepecki R, Nowosad B, Skrzyzala I, Roborzynski M, Fudalewicz-Niemczyk W, Skalska M, Malczewski A, Gruner L: Genetic resistance to gastrointestinal nematode parasites in Polish long-wool sheep. International Journal of Parasitology 1998 , 28( I I): | 797-1804

19. Eady SJ, Woolaston RR, Mortimer SI, Lewer RP, Raadsma HW, Swan AA, Ponzoni RW: Resistance to nematode parasites in Merino sheep: sources of genetic variation. Australian Journal of Agricultural Research 1996, 47(6):895-915.

20. Gruner L, Aumont G, Getachew T, Brunel JC, Pery C, Cognie Y, Guerin Y: Experimental infection of Black Belly and INRA 40 I straight and crossbred sheep with trichostrongyle nematode parasites. Vet Parasitol 2003, I I 6(3):239-249.

21. Crawford AM, Phua SH, McEwan JC, Dodds KG, Wright CC, Morris CA, Bisset SA, Green RS: Finding disease resistance QTL in sheep. Animal Biotechnology 1997, 8(I): | 3-22.

22. Hulme DJ, Nicholas FW, Windon RG, Brown SC, Beh KJ: The MHC class II region and resistance to an intestinal parasite in sheep. Journal of Animal Breeding and Genetics 1993, I I 0(6):459-472.

23. Charon KM, Moskwa B, Kuryl J, Gruszczynska J, Rutkowski R: Relationship between polymorphism in locus OMHCI (MHC class I) and resistance to nematodes in Polish Heatherhead Sheep. Animal Science Papers and Reports 200I, I9(4):285-292.

24. Charon KM, Moskwa B, Rutkowski R, Gruszczynska J, Swiderek W: Microsatellite polymorphism in DRBI gene (MHC class II) and its relation to nematode faecal egg count in Polish Heath Sheep. Journal of Animal and Feed Sciences 2002, I I ( I):47-58.

25. Buitkamp J, Bishop SC, Stear MJ: The identification of sheep genetically resistant to the nematode Teladorsagia circumcincta. In Proceedings of the 7th World Congress on Genetics Applied to Livestock Production: 2002; Montpellier; France INRA; 2002: I-4

26. Paterson S, Wilson K, Pemberton JM: Major histocompatibility complex variation associated with juvenile survival and parasite resistance in a large unmanaged ungulate population (Ovis aries L.). Proceedings of the National Academy of Sciences 1998 , 95(7):37|4-37|9.

27. Coltman DW, Wilson K, Pilkington JG, Stear MJ, Pemberton JM: A microsatellite polymorphism in the gamma interferon gene is associated with resistance to gastrointestinal nematodes in a naturally-parasitized population of Soay sheep. Parasitology 200I, I 22(5):57I-582.

28. Paterson KA, McEwan JC, Dodds KG, Crawford AM: Fine mapping a locus affecting host resistance to internal parasites in sheep. Proceedings Association for the Advancement of Animal Breeding and Genetics 2001, I 4:353-356.

29. Beh KJ, Hulme DJ, Callaghan MJ, Leish Z, Lenane I, Windon RG, Maddox JF: A genome scan for quantitative trait loci affecting resistance to Trichostrongylus colubriformis in sheep. Animal Genetics 2002, 33(2):97-106.

30. Marshall K, van der Werf JHJ, Maddox JF, Graser HU, Zhang Y, Walkden-Brown SW, Kahn L: A genome scan for quantitative trait loci for resistance to the gastrointestinal parasite Haemon- 
chus contortus in sheep. Proceedings Association for the Advancement of Animal Breeding and Genetics 2004, 16:1 I5 - I I 18.

31. Raadsma HW, Margawati ET, Piedrafita D, Estuningsih E, Widjajanti S, Beriajaya, Subandriyo, Thomson P, Spithill TS: Towards molecular genetic characterisation of high resistance to internal parasites in Indonesian Thin Tail sheep. In Proceedings of the 7th World Congress on Genetics Applied to Livestock Production: 2002; Montpellier; France INRA; 2002: 13-19.

32. Davies G, Stear MJ, Benothman M, Abuagob O, Kerr A, Mitchell S, Bishop SC: Quantitative trait loci associated with parasitic infection in Scottish blackface sheep. Heredity 2006, 96(3):252-258.

33. Beavis WD: The power and deceit of QTL experiments: lessons from comparative QTL studies: Proc. 49th Annual Corn \& Sorghum Industry Research Conference, Washington, DC. ; 1994:250-266.

34. Carlborg O, Jacobsson L, Ahgren P, Siegel P, Andersson L: Epistasis and the release of genetic variation during long-term selection. Nat Genet 2006, 38(4):418-420.

35. Jacobsson L, Park HB, Wahlberg P, Fredriksson R, Perez-Enciso $M$, Siegel PB, Andersson L: Many $Q T L s$ with minor additive effects are associated with a large difference in growth between two selection lines in chickens. Genet Res 2005, 86(2): I I5- I 25.

36. Hardenbol P, Yu F, Belmont J, Mackenzie J, Bruckner C, Brundage T, Boudreau A, Chow S, Eberle J, Erbilgin A, Falkowski M, Fitzgerald R, Ghose S, lartchouk O, Jain M, Karlin-Neumann G, Lu X, Miao X, Moore B, Moorhead M, Namsaraev E, Pasternak S, Prakash E, Tran K, Wang Z, Jones HB, Davis RW, Willis TD, Gibbs RA: Highly multiplexed molecular inversion probe genotyping: over 10,000 targeted SNPs genotyped in a single tube assay. Genome Research 2005, I5(2):269-275.

37. McRae AF, McEwan JC, Dodds KG, Wilson T, Crawford AM, Slate J: Linkage disequilibrium in domestic sheep. Genetics 2002, 160(3): III3-II22.

38. Baker RL, Watson TG, Bisset SA, Vlassof A, Douch PGC: Breeding sheep in New Zealand for resistance to internal parasites: Research results and commercial application. In Breeding for Disease resistance in Sheep Edited by: Gray GD, Woolaston RR. Melbourne, Australian Wool Corporation; 1991:19-132.

39. Bisset SA, Vlassoff A, Douch PGC, Jonas WE, West CJ, Green RS: Nematode burdens and immunological responses following natural challenge in Romney lambs selectively bred for low or high faecal worm egg count. Veterinary Parasitology 1996, 6I(3-4):249.

40. Whitlock HV: Some modifications of the McMaster helminth egg counting technique and apparatus. Journal of the Council for Scientific and Industrial Research 1948, 2 1:177-180.

4I. Roberston TG, Elliott DG: The laboratory assessment of worm parasite populations in sheep. New Zealand Journal of Agricultural Research 1966, 9:350-3358.

42. Douch PG, Green RS, Risdon PL: Antibody responses of sheep to challenge with Trichostrongylus colubriformis and the effect of dexamethasone treatment. International Journal of Parasitology 1994, 24(7):921-928.

43. Shaw RJ, McNeill MM, Gatehouse TK, Douch PG: Quantification of total sheep IgE concentration using anti-ovine IgE monoclonal antibodies in an enzyme immunoassay. Vet Immunol Immunopathol 1997, 57(3-4):253-265.

44. www.rampage.co.nz: .

45. Crawford AM, Buchanan FC, Swarbrick PA: Ovine dinucleotide repeat polymorphism at the MAFI8 locus. Animal Genetics 1990, 2 I(4):433-434.

46. [http://rubens.its.unimelb.edu.au/ jillm/jill.htm].

47. Lander ES, Green P: Construction of multilocus genetic linkage maps in humans. Proceedings of the National Academy of Science 1987, 84:2363-2367.

48. Maddox JF, Davies KP, Crawford AM, Hulme DJ, Vaiman D, Cribiu EP, Freking BA, Beh KJ, Cockett NE, Kang N, Riffkin CD, Drinkwater R, Moore SS, Dodds KG, Lumsden JM, van Stijn TC, Phua SH, Adelson DL, Burkin HR, Broom JE, Buitkamp J, Cambridge L, Cushwa WT, Gerard E, Galloway SM, Harrison B, Hawken RJ, Hiendleder S, Henry HM, Medrano JF, Paterson KA, Schibler L, Stone RT, van Hest B: An enhanced linkage map of the sheep genome comprising more than 1000 loci. Genome Research 200I, I I: I275-I 289.

49. Spelman RJ, Coppieters W, Karim L, Van Arendonk JAM, Bovenhuis $H$ : Quantitative trait loci analysis for five milk production traits on chromosome six in the Dutch Holstein-Friesian population. Genetics 1996, 144(4): 1799-1807.

50. Knott SA, Elsen JM, Haley CS: Methods for multiple-marker mapping of quantitative trait loci in half-sib populations. Theoretical and Applied Genetics 1996, 93:71-80.

51. Churchill GA, Doerge RW: Empirical threshold values for quantitative trait mapping. Genetics 1994, I38:963-97I.

52. Visscher PM, Thompson R, Haley CS: Confidence intervals in QTL mapping by bootstrapping. Genetics 1996, I43:1013-1020.

53. Lander ES, Kruglyak L: Genetic dissection of complex traits guidelines for interpreting and reporting linkage results. Nature Genetics 1995, I I:24 |-247.
Publish with Biomed Central and every scientist can read your work free of charge

"BioMed Central will be the most significant development for disseminating the results of biomedical research in our lifetime. "

Sir Paul Nurse, Cancer Research UK

Your research papers will be:

- available free of charge to the entire biomedical community

- peer reviewed and published immediately upon acceptance

- cited in PubMed and archived on PubMed Central

- yours - you keep the copyright

Submit your manuscript here:

http://www.biomedcentral.com/info/publishing_adv.asp 